\title{
HEAVY VEHICLE MULTI-BODY DYNAMIC SIMULATIONS TO ESTIMATE SKIDDING DISTANCE
}

\author{
Mahdieh ZAMZAMZADEH ${ }^{1}$, Ahmad Abdullah SAIFIZUL ${ }^{2}$, \\ Rahizar RAMLI ${ }^{3}$, Ming Foong SOONG ${ }^{4}$ \\ 1,2,3,4 Department of Mechanical Engineering, Faculty of Engineering, \\ University of Malaya, Kuala Lumpur 50603, Malaysia \\ ${ }_{1,3,4}$ Advanced Computational and Applied Mechanics Research Group, \\ Faculty of Engineering, University of Malaya, Kuala Lumpur 50603, Malaysia
}

Received 02 March 2017; accepted 21 September 2017

\begin{abstract}
The skid mark is valuable for accident reconstruction as it provides information about the braking behaviour drivers and the speed of heavy vehicles. However, despite its importance, there is currently no mathematical model available to estimate skidding distance (SD) as a function of vehicle characteristics and road conditions. This paper attempts to develop a non-linear regression model that is capable of reliably predicting the skidding distance of heavy vehicles under various road conditions and vehicle characteristics. To develop the regression model, huge data sets were derived from complex heavy vehicle multi-body dynamic simulation. An emergency braking simulation was conducted to examine the skidding distance of a heavy vehicle model subject to various Gross Vehicle Weight (GVW) and vehicle speeds, as well as the coefficient of friction of the road under wet and dry conditions. The results suggested that the skidding distance is significantly affected by Gross Vehicle Weight, speeds, and coefficient of friction of the road. The improved non-linear regression model provides a better prediction of the skidding distance than that of the conventional approach thus suitable to be employed as an alternative model for skidding distance of heavy vehicles in accident reconstruction.
\end{abstract}

Keywords: crash avoidance, emergency braking, road safety, road surface, skid mark, wet road, wheel lock-up.

\section{Introduction}

Today, the heavy vehicle is still the most flexible and one of the most efficient ways to transport freight all over the world. However, truck accidents are still increasing everywhere. Although many traffic regulations and limitations have been imposed, crashes are still being reported daily. Several studies have reported critically injured or killed occupants are more frequent in accidents involving heavy vehicles compared to those involving passenger cars (S. Chen \& F. Chen, 2009). Therefore, efforts to reduce the risk of heavy vehicle accidents, such as the understanding of vehicle behaviour during braking, have always been essential in the research field of traffic safety (Ong \& Fwa, 2009).

In developing countries such as Malaysia, from a news report in 2012, 70\% of road accidents are due to brake failure. It is known, one of the important elements in heavy vehicle accidents is the possibility of truck skidding - the sliding of locked wheels along the ground - especially during emergency braking for heavy vehicles without Anti-lock Braking System (ABS) (Wallman \& Åström, 2001). The statistics have highlighted that skidding-related accidents have a higher record, and this logically translates to greater fatalities and economic costs. Thus, due to the high rate of reports on heavy vehicle accidents, it is necessary to take into account the skidding issue of heavy vehicles, for instance, the skidding distance is related to the skid marks, whenever heavy vehicle safety is concerned.

While skidding contributes to a substantial portion of heavy vehicle crashes and is therefore worth looking into vehicle safety studies, there are also many other factors relevant to truck stability and braking performance (Harwood, Torbic, Richard, Glauz, \& Elefteriadou, 2003; Limpert \& Andrews, 1987). Various studies have shown that the heavy vehicles' characteristic, loading condition, and speed play significant roles in road safety (Fancher \& Campbell, 1995; Gobbi, Mastinu, \& Previati, 2014; Seipel,

*Corresponding author. E-mail: saifizul@um.edu.my 
Baumann, Hermanutz, \& Winner, 2013). Additionally, the tire and pavement friction are also serious contributing factors that lessen the potential for crashes. Any road condition change, from dry asphalt or even concrete to ice transition, influences the parameters of the sliding friction function and is a very important parameter in wheel lockup and vehicle skidding (Bartlett \& Wright, 2010; Flintsch, McGhee, de León Izeppi, \& Najafi, 2012; Goudie, Bowler, Brown, Heinrichs, \& Siegmund, 2000; Hall et al., 2009; Henry, 2000). The relation between the vertical and horizontal tire forces is also very important because it is the resistance of the road surface to skidding or sliding of a vehicle (Asi, 2007; Deur, Asgari, \& Hrovat, 2004; Noyce, Bahia, Yambo, \& Kim, 2005; Ray, 1997).

Hence, the major factors that lead to high risk accidents are vehicle load, speed and road coefficient of friction. Many studies have shown clearly that heavy vehicle crashes happen due to these risk factors that cause the truck to lose control and not be able to stop safely (Bullen \& Ruller, 1998; Ong \& Fwa, 2009). Thus, considering these factors is vital to reduce the number of fatalities, injuries, and property damage due to heavy vehicle crashes (Dee \& Sela, 2003; Ghadiri, Prasetijo, Sadullah, Hoseinpour, \& Sahranavard, 2013).

Heavy vehicle drivers usually exert a large pedal force when there is an urgent situation or unexpected object on the road. If any accidents happen in this situation, the most popular and well-known input to reconstruct the accident is mostly the tire skid mark. It means first speed is estimated by measuring the length of the skid mark. However, to identify an accurate cause of the accident, estimation of pre-braking speed under different vehicle and road conditions has to be calculated by estimating skidding distance through tire skid marks. As mentioned the estimated speed is applicable as of the most important pre-crash requirement.

Furthermore, apparent tire skid marks on the road surface, which are derived from the friction between the tire and the road, are very important record during accident reconstruction. They provide a wide range of information and allow the road engineers to make calculations and finally conclusions about vehicle speed for reconstruction purposes in terms of determining the cause of accidents. Recently, simulation techniques are being used to know more about pre-conditions of tire marks generation and also vehicle and road parameters that effects on their intensity.

However, unfortunately, presently there are only a few studies that have been carried out on the heavy vehicle skidding distance and skid mark length in relation with the mentioned risk factors, leading to a lack of detailed understanding of the effect of these factors on skid mark length. This is probably because of the absence of a comprehensive theoretical, analytical or numerical model. In fact, past studies on skidding and skid marks have been largely limited to experimental field tests and analysis of accident data (Bedsworth, Butler, Rogers, Breen, \& Fischer, 2013; Kim, Jung, Ryu, \& Oh, 2012). However, fullscale experimental studies are time consuming, require intensive workforce and are costly to conduct, despite improvements in the techniques of skid mark measurements in recent years. This is particularly relevant to heavy vehicles as the few types of research conducted in the past were mostly focused on passenger cars (Seipel et al., 2013). Among the related studies, Ong (Ong \& Fwa, 2009) recommended a strong analytical model for heavy vehicles using the finite element method, but even this analytical simulation model focused merely on the skid resistance behaviour of heavy vehicle tires rather than on skidding distance.

In this paper, heavy vehicles' skidding distance due to emergency braking was investigated precisely, through a multi-body dynamic simulation of a real truck model. The first aim of the study is to evaluate the effect of various risk factors on the trucks' skidding distance or skid mark length, including its Gross Vehicle Weight (GVW), speed and the road surface condition simultaneously. Then, as it is very complicated to consider all the risk factors in real conditions, it will be helpful to introduce a reliable and efficient way to estimate skid mark length. Therefore, more importantly, the second aim of the study involves introducing a mathematical model for skidding distance or skid mark length based on a reliable non-linear regression model where all risk factors were considered. With the proposed model, it is envisaged, the skidding distance estimation will provide a more realistic depiction of the real situation for safety analysis involving heavy vehicles. Controlled studies for tire skid mark illustrated that it generates as soon as the wheel lock up happens and vehicle starts to skid along the road.

\section{Wheel lock-up}

Past researchers have clarified some aspects of the heavy vehicle skidding accidents during emergency braking require the knowledge of wheel lock-up (Vangi \& Virga, 2007; Xiao, Kulakowski, \& EI-Gindy, 2000). In fact, the skidding phenomenon of a vehicle under braking is identified by the occurrence of wheel lock-up. When a driver applies the brake with excessive pedal force, it is possible for the brakes to grip the wheels tight enough to stop them from rotating before the vehicle comes to a stop. This causes the vehicle to skid along the road without any control. Undoubtedly, heavy vehicles have more difficulty in braking during wheel lock-up than cars since the stopping scenario during wheel lock-up is not safe. Therefore, trucks must have controlled braking rather than locked wheels (Harwood et al., 2003).

The key variable to describe the state of wheel lockup is the wheel slip ratio. The slip ratio is usually used to check for wheel lock-up of each wheel on a vehicle in simulations or experimental tests involving different conditions. Slip ratio is defined as Eq. (1) (Pacejka, 2006):

$$
\text { Slip ratio }=-\frac{V_{x}-\omega R_{e}}{V_{x}},
$$

where $V_{x}$ - longitudinal vehicle speed, $\mathrm{m} / \mathrm{s} ; \omega$ - angular 
velocity of tire, $\mathrm{rad} / \mathrm{s} ; R_{e}$ - effective radius of tires, $\mathrm{m}$; (it is the radius of tire when there is no external torque around the spin axis).

Following the definition, a free-rolling wheel corresponds to $V_{x}-\omega R_{e}=0$ that results in slip ratio $=0$. Conversely, a wheel lock-up event corresponds to $\omega=0$ for any non-zero longitudinal velocity (the wheel stops rotating even when the vehicle is still moving). Thus, wheel lock-up is identified from slip ratio $=-1$.

Indeed, some researchers have outlined and presented the results of wheel lock-up, which occurs during emergency braking (Jones, 2013; Pacejka, 2006). For example, Ervin (Ervin \& Winkler, 1988) worked on the effect of deceleration rate, tire friction and braking efficiency on wheel lock-up. Xuanfeng, Yingchun, Guang, Chaosheng, and Guozeng (2011) have done considerable effort to investigate the mass effects on changes of vehicle centre of gravity and finally on the occurrence of wheel lock-up. All related researches suggested many aspects, which play a role in wheel lock-up, but it is very useful to describe directly the effects of the three mentioned major risk factors on wheel lock-up to point out their effects on skidding.

\subsection{Skid mark and accident reconstruction}

Skid mark is very closely associated with wheel lock-up. Generally, when a vehicle experiences wheel lock-up and subsequently skids, there are tire marks printed on the road. In accident reconstruction studies, these are called skid marks and play a central role in the reconstruction of accidents since they provide valuable information about the behaviour of the driver during braking, the initial speed of the vehicle and much more useful information about the trajectory of the vehicle. Presently, forensic engineers measure the skid mark length (or in other words, represents the skidding distance) and apply the measurements to a formula that is called the "Skid to Stop Formula". This formula allows them to estimate the speed of the vehicle during emergency braking. The formula is Eq. (2):

$$
\mathrm{SD}=\frac{V^{2}}{254 f_{s}},
$$

where SD - skid mark length, $\mathrm{m} ; V$ - vehicle speed, $\mathrm{km} / \mathrm{h}$; $f_{s}$ - coefficient of friction.

The formula is available reversely as a model for skidding distance. However, even in its original intended use to back-estimate vehicle speed from skidding, several limitations do exist and have been mentioned by past studies. For instance, Neptune, Flynn, Chavez, and Underwood (1995) noted on such a limitation that the formula does not account for the energy converted to work during the transient portion of the braking process. Consequently, a more accurate estimation that considered the pre-skidding braking was proposed, but the improved estimation was still generally based on the simplistic formula (Neptune et al., 1995). Meanwhile, more recent researches have the focus on braking distance estimation instead due to the development of some active safety systems like the colli- sion avoidance system. For instance, Sharizli, Ramli, Karim, and Saifizul (2013) proposed a non-linear-regression model on braking distance of several multi-axle heavy vehicles, considering speed and vehicle factors, and subsequently incorporated this in the formulation of a developed safety indicator for heavy vehicle close-following situation (Sharizli, Ramli, Karim, \& Saifizul, 2015). The studies indicate the importance of incorporating GVW as a vehicle dynamic parameter in the analysis of the braking situation; however, consideration on skidding was not included. Meanwhile, back to skidding distance estimation, the current formula considers only vehicle speed and coefficient of friction as the parameters while other similarly significant factors such as vehicle dynamic parameters are not considered. In contrast, the model introduced in this study considers GVW (a vehicle dynamic parameter) along with vehicle speed and road coefficient of friction simultaneously. It provides a reliable estimation of skid mark length under a more comprehensive set of conditions.

\section{Methodology}

This study on heavy vehicle skidding was carried out through multi-body dynamic simulation of a virtual truck model. The virtual test is one of the two main methods commonly employed in studies related to braking performance and wheel lock-up of a vehicle, with the other method being an actual experimental test (Steets, Chan, Sandu, \& Ballew, 2010). Evidently, the instrumentation process in the prototype vehicle to carry out the actual tests and obtain the related output signals consumes a lot of time and cost. Moreover, in the context of this study, some tests at high speeds with the overloaded cab on the low coefficient of friction roads are very unsafe and difficult to implement physically. On the other hand, the use of multi-body dynamic simulation approach in this study makes it possible to incorporate various factors that have an effect on heavy vehicle skidding (vehicle load, speed and road surface) as these would be varied conveniently in the virtual environment for repetitive testing. It is also consistent across several studies that employed the simulation approach to investigate the safety performances and address the reliable dynamic performances such as braking (Sharizli, Ramli, Karim, \& Abdullah, 2014). As an overview, there are four main steps involved in the study: the modelling of a virtual heavy vehicle, the model validation, the emergency braking simulation to generate vehicle responses during skidding, and the analysis of the results.

\subsection{Vehicle modelling}

The first step of the study was to develop a virtual model, which would accurately reflect an actual heavy vehicle for use in the subsequent braking simulation. For this study, the 4-axle Single Unit Truck (SUT) was used, since it is this category that contributes most to heavy vehicle accidents involving skidding, according to a recent study (Abdullah, 2011). The specifications of the heavy vehicle model were 
extracted from several sources, including actual measurements and the general heavy vehicle design specifications from the manufacturer. The actual parameters were input into braking system to initialize the braking model. Some of the general specifications of the relevant SUT are shown in Table 1.

The model was created in MSC.ADAMS/Truck which is a multi-body dynamic simulation software (Figure 1). Conventionally, the multi-body model simulation approach is seen to be capable of predicting accurate vehicle response. For instance, Sharizli (Sharizli et al., 2014) described MSC.ADAMS/Truck as a reliable truck-based modelling and simulation software in developing realistic heavy vehicle model. In this study, the model was created as detailed as possible, for example, by incorporating parabolic leaf spring suspension, air drum brake and tire (using the Pacejka-type tire model), to ensure the performance of model to be as close as the actual heavy vehicle. Furthermore, since the Pacejka -type tire model is a semi-empirical formula, which represents tire behaviour (such as the longitudinal tire force), and its input are derived from real tire measured data, it was used reliably in the modelling of the tires for multi-body dynamic simulation of this study. Many researchers have widely used it as the contiguous model to the experimental results (Schmid, 2011). In this study, due to the non-linear tire characteristics, which have a direct effect on the braking phenomenon and skidding concerns, the tire model was developed close to the real tire specification to fulfil the study requirements. Table 2 shows the specification of PAC2002 tire model in MSC.ADAMS/Truck that was used in the study.

\subsection{Experimental procedure}

Following model development, it was imperative to validate the SUT model by comparing the simulated vehicle response against the experimental data and verify the model accuracy, thus, the model performance was compared to experimental test results. The test series consisted of different loading configurations, namely empty and a full payload. Each condition included a baseline run in terms that all brakes were functioning properly. Moreover, the test series consisted of braking for different initial speeds, one initially started from $40 \mathrm{~km} / \mathrm{h}$ to $80 \mathrm{~km} / \mathrm{h}$. The braking tests were conducted to record braking distances (BD) for different initial braking speeds, then compared with the simulation results. In addition, the experimental tests were performed according to the tests conducted according to the Federal Motor Vehicle Safety Standard (FMVSS) No. 121, Air Brake Systems (Garrott \& Guenther, 1982). Table 3 and Table 4 compare the BD. The simulation results was compared with experimental ones for two different loading conditions, empty and full payload configurations.

As Table 3 and Table 4 show in detail, the simulation correlated quite well with the experiment. In particular, for the empty load configuration, with an average margin of compliance of $1.88 \%$ and no more than $3.70 \%$, it was deemed sufficient for the vehicle model to accurately predict braking situations. Meanwhile, the average margin of compliance was observed to be higher (5.83\%) for the full load configuration. The discrepancy between simulation and experiment is believed to be attributed to a few factors, which cannot be represented in the specific modelling environment, namely the aerodynamic effect and the possible deteriorated performance of the actual tires

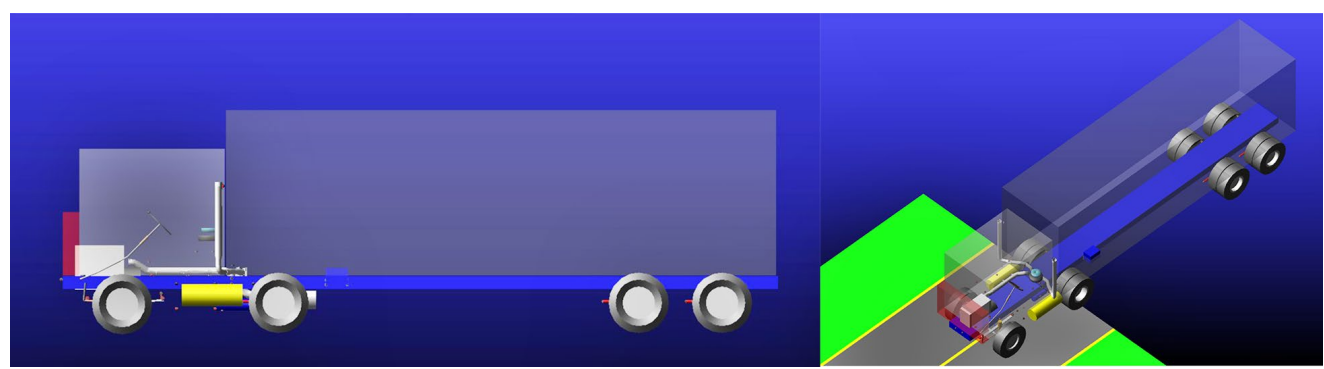

Figure 1. The modelling environment and the truck model in simulation software

Table 1. SUT general specifications

\begin{tabular}{|l|l|c|}
\hline \multicolumn{1}{|c|}{ Designation } & \multicolumn{2}{|c|}{ Parameters } \\
\hline Dimensions, $\mathrm{m}$ & Wheelbase & 10.91 \\
\hline $\begin{array}{l}\text { Weight, kg } \\
\text { equivalent }\end{array}$ & Front Axle & 6840 \\
& Rear Axles & 3940 \\
& Total & 10780 \\
\hline \multirow{3}{*}{ Suspension } & Front axle 3 leaf parabolic leaf springs and \\
& shock absorbers with anti-roll bar \\
& Drive axles Multilink suspension, shock \\
& absorber and air bag \\
\hline Brakes & Air Drum Brakes \\
\hline Tires & Steer and Drive- 315/80 R 22.5 \\
\hline
\end{tabular}

Table 2. Tire specification

\begin{tabular}{|l|c|}
\hline \multicolumn{2}{|c|}{ PAC2002 } \\
\hline Tire & 315/80R22.5 \\
\hline Section width, $\mathrm{mm}$ & 315 \\
\hline Aspect ratio & 548 \\
\hline Unloaded radius, $\mathrm{mm}$ & 800 \\
\hline Inflation pressure, $\mathrm{kPa}$ & 280 \\
\hline Rim radius, $\mathrm{mm}$ & 229 \\
\hline Rim width, $\mathrm{mm}$ & $+/-1.5$ \\
\hline Wheel slip & \\
\hline
\end{tabular}


fitted on the test vehicle due to tread wear. In addition, the higher average margin of compliance for the full load configuration is likely due to a difference in load distribution between the multi-body modelling environment and the actual scenario. With all these considered, the model validation was deemed acceptable.

\subsection{Emergency braking}

Once the four-axle SUT model was validated, it was subsequently used to simulate an emergency braking event in MSC.ADAMS/Truck. For every test, the SUT model was set to travel at constant forward velocity before the initiation of braking. The brake pedal force was then applied continuously until the heavy vehicle decelerated to a standstill condition. The test was then repeated by changing the amount of brake pedal force to reach wheel lock-up. For this simulation, the straight-line braking on a straight, flat and even road section was assumed. In addition, due to the continuous application of brake pedal force, any skidding situation was logically assumed to be braking-induced and uninterrupted.

The simulation was used to check the possibility of wheel lock-up under various conditions, namely the vehicle load, speed and road surface conditions. Correspondingly, three influential factors were considered in the simulation: the GVW of the truck, vehicle speed and road coefficient of friction. These factors were varied according to Table 5. Based on the table, 6000 braking tests were carried out that covered a wide range of load, speed and road surfaces. Specifically, the GVW values ranged from the empty (11 t), semi full (21 t), and full loading (31 t) conditions of the model to overloading conditions (41 t). Meanwhile, for heavy vehicle speed in the simulations, the adopted values ranged from typical speeds for urban roads $(40-60 \mathrm{~km} / \mathrm{h})$ to typical highway speeds $(80 \mathrm{~km} / \mathrm{h})$ to cover all used speed ranges. Finally, for the road coefficient of friction, normal asphalt pavement considered as the road surface type, with different coefficient of friction values, that was employed to represent different road surface conditions, ranging from an undersirable slippery condition such as wet road situation to the ideal traction condition such as dry road situation. The adopted road coefficients of friction were based on experimentally determined values in several past studies (Gustafsson, 1997; Noon, 1992). It should be highlighted that the traction performance of a tire, is represented as a $\mu$-slip curve with the coefficient of friction reaching peak value between 0.1 and 0.4 slip ratio (Oh \& Lee, 2014) and the values taken for this study all corresponded to the sliding mode of friction coefficient, in other words at slip ratio equals to 1 . All of these are supposed to correctly exploit the vehicle skidding scenario.

\subsection{Skidding vehicle data generation and interpretation}

The final stage of the study involved data generation and interpretation. From the 6000 tests, excluding the cases where wheel lock-up did not occur, 1800 tests were cho- sen to generate the data sets. From the data sets, several relevant variables were analysed, including the longitudinal velocity, wheel's angular velocity, slip ratio, time and BD. These were used to identify wheel lock-up occurrence and subsequently to determine the skidding distance (SD). The results were obtained base on the theory at higher slip ratios, the tire longitudinal force decreases, and when wheel lock-up happens due to low tire traction, the vehicle starts to skid.

The skidding distance data under various combinations of conditions was then compiled to study the effect of these conditions on heavy vehicles skid mark, and a model based on non-linear multiple regression was introduced to represent skidding distance.

Table 3. Comparison between experiment and simulation results for braking distances at various speeds (Empty Configuration)

\begin{tabular}{|c|c|c|c|}
\hline \multirow{2}{*}{$\begin{array}{l}\text { Vehicle } \\
\text { speed, } \\
\mathrm{km} / \mathrm{h}\end{array}$} & \multirow{2}{*}{$\begin{array}{c}\begin{array}{c}\text { Experiment } \\
(\text { FMVSS 121) }\end{array} \\
\begin{array}{c}\text { Braking } \\
\text { distances, } \mathrm{m}\end{array}\end{array}$} & \multicolumn{2}{|c|}{ Simulation } \\
\hline & & $\begin{array}{c}\text { Braking } \\
\text { distances, } \mathrm{m}\end{array}$ & $\begin{array}{c}\text { Margin of } \\
\text { compliance, \% }\end{array}$ \\
\hline 40 & 12.97 & 12.49 & 3.70 \\
\hline 50 & 20.09 & 19.99 & 0.47 \\
\hline 60 & 28.94 & 29.22 & 1.00 \\
\hline 70 & 38.88 & 39.58 & 1.79 \\
\hline 80 & 50.06 & 51.31 & 2.48 \\
\hline
\end{tabular}

Table 4. Comparison between experiment and simulation results for braking distances at various speeds (Full Payload Configuration)

\begin{tabular}{|c|c|c|c|}
\hline \multirow{2}{*}{$\begin{array}{l}\text { Vehicle } \\
\text { speed, } \\
\mathrm{km} / \mathrm{h}\end{array}$} & \multirow{2}{*}{$\begin{array}{c}\begin{array}{c}\text { Experiment } \\
(\text { FMVSS 121) }\end{array} \\
\begin{array}{c}\text { Braking } \\
\text { distances, } \mathrm{m}\end{array}\end{array}$} & \multicolumn{2}{|c|}{ Simulation } \\
\hline & & $\begin{array}{c}\text { Braking } \\
\text { distances, } \mathrm{m}\end{array}$ & $\begin{array}{c}\text { Margin of } \\
\text { compliance, \% }\end{array}$ \\
\hline 40 & 13.58 & 12.840 & 5.45 \\
\hline 50 & 21.38 & 20.061 & 6.17 \\
\hline 60 & 30.60 & 28.870 & 5.65 \\
\hline 70 & 41.14 & 38.447 & 6.55 \\
\hline 80 & 53.08 & 50.250 & 5.33 \\
\hline
\end{tabular}

Table 5. Simulation input parameters

\begin{tabular}{|c|c|c|c|}
\hline \multicolumn{4}{|c|}{ Analysis influential factors } \\
\cline { 1 - 3 } $\begin{array}{c}\text { Gross vehicle } \\
\text { weight, } t\end{array}$ & $\begin{array}{c}\text { Coefficient } \\
\text { of friction, } \mu\end{array}$ & $\begin{array}{c}\text { Vehicle speed, } \\
\mathrm{km} / \mathrm{h}\end{array}$ & $\begin{array}{c}\text { Pedal force, } \\
\text { N, unit? }\end{array}$ \\
\cline { 1 - 3 } 11 & 0.3 & 40 & \multirow{2}{*}{ 10 to 600} \\
\cline { 1 - 3 } (steps of 10$)$
\end{tabular}




\section{Results and discussion}

\subsection{Impact of Gross Vehicle Weight, speed and road surface condition on Skidding Distance}

Following the emergency braking simulation, the SD data of the heavy vehicle due to wheel lock-up was compiled. The results were then plotted to investigate the effects of GVW, speed, and road coefficient of friction on the SD or skid mark length of the tested heavy vehicle, as shown in Figures 2-4. In general, the simulation results confirmed some known relations between SD and the influential factors. Additionally, the results also proved the significance of these factors.

To quantify the impact at different levels of vehicle load on the skid mark length during skidding, a sequence of different GVW values was analysed. Figure 2 illustrates the variation of SD as a function of the GVW of the heavy vehicle for several speeds and road coefficients of friction. It is clearly seen there is an increase in SD with an increase in GVW, and this is especially significant at high vehicle speeds. Meanwhile, plots for the SD of heavy vehicles at low vehicle speed have only shown a slight growth with an increase in GVW. This means when the heavy vehicle is traveling at its minimum speed, the GVW factor does not significantly affect SD on both wet and dry road surface conditions (different road coefficients of friction).

From the result, it is important to note that the greater the load of the heavy vehicle the longer the SD will be for the truck to stop. Thus, in an emergency, an overloaded truck will not be able to stop at the same distance as a non-overloaded truck, no matter what is the condition of the road surface. Overloading of a truck represents a safety risk. From another perspective, Figures $3 \mathrm{a}-3 \mathrm{~d}$ compares the variation of SD under different road surface conditions (road coefficient of friction, $\mu$ ), ranging from a wet road surface $(\mu=0.3)$ to the dry road surface (a maximum of $\mu=0.7$ ), for several speeds and GVW. From the plots, it is clearly shown $S D$ is not only affected by GVW as discussed previously, but also by road surface condition. In this case, the SD decreases for an increase in road coefficient of friction. For example, the tested heavy vehicle with a GVW of $41 \mathrm{t}$, traveling at a speed of $80 \mathrm{~km} / \mathrm{h}$ on a wet road $(\mu=0.3)$ needed around $200 \mathrm{~m}$ to stop (Point A in Figure 3d). As for the truck with the same conditions except traveling on a dry road $(\mu=0.7)$, it only needed around $100 \mathrm{~m}$ to stop (Point B in Figure 3d). Hence, it is deduced wet road surface with a lower coefficient of friction results in a longer SD due to a greater chance of wheel lock-up during the braking of a heavy vehicle.

Lastly, the relation between SD and vehicle speed, considering several GVW and road coefficients of friction, are shown in Figure 4. It is observed the SD tends to rise proportionally with an increase in vehicle speed, regardless of the other factors. From the plots, it is seen the SD for the tested heavy vehicle at high speed is approximately four times the SD at low speed that is quite significant considering the vehicle speed is higher only by a factor of two. Therefore, vehicle speed condition also has a significant effect on heavy vehicle safety as a truck traveling at high speed has a greater chance of not being able to stop safely, especially in the close-following situation.

Overall, the analysis has confirmed the expected skidding distance behaviour under the influence of the investigated factors. Specifically, the SD of a heavy vehicle is noticeably affected by all three factors, namely GVW, speed and road coefficient of friction that respectively represent vehicle load, vehicle speed, and road surface condition. For example, the GVW of a relatively larger truck produces a greater SD during emergency braking in all situations. However, although this means the empty truck contributes to the shortest SD, other factors such as undesirable truck speed and road surface condition will still turn it into a critical situation. Therefore, all three factors adopted in the study have to be considered simultaneously in the modelling of the skid mark. a)

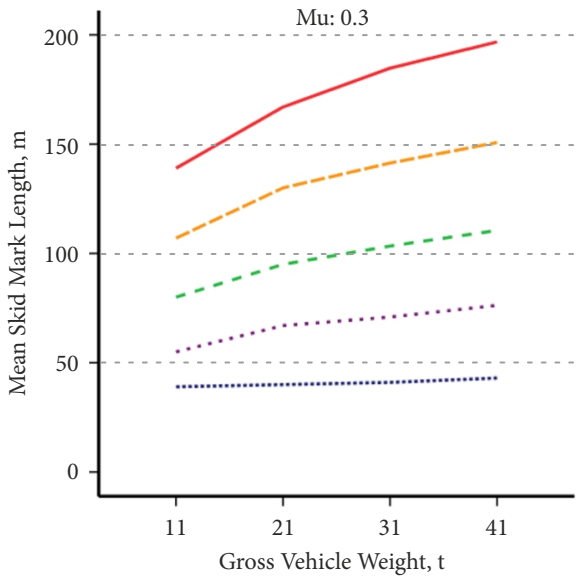

b)

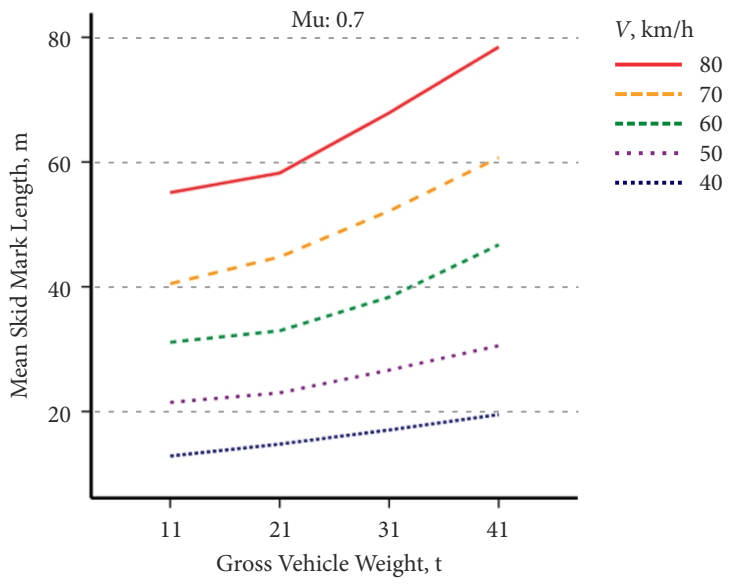

Figure 2. Effect of Gross Vehicle Weight on Skidding Distance under different speed and $\mu$ conditions 
a)

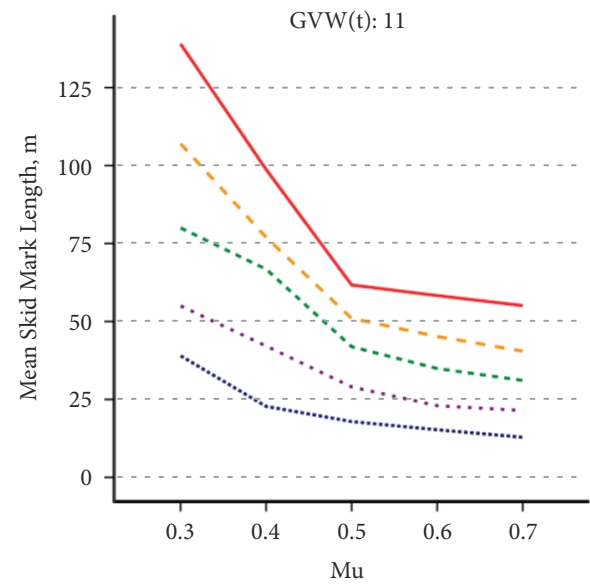

c)

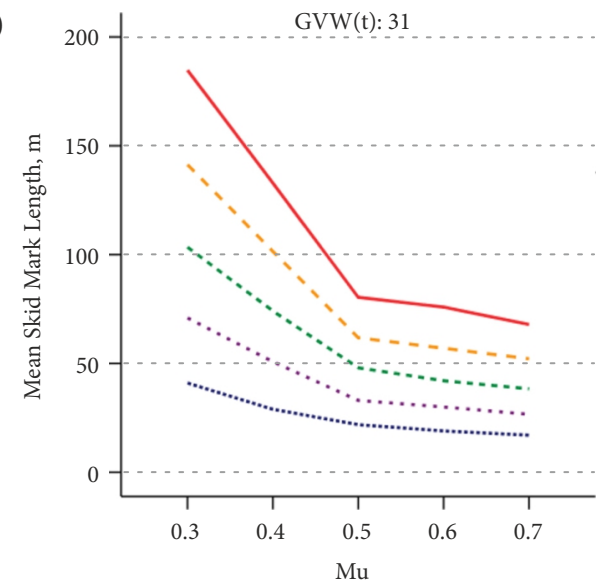

b)

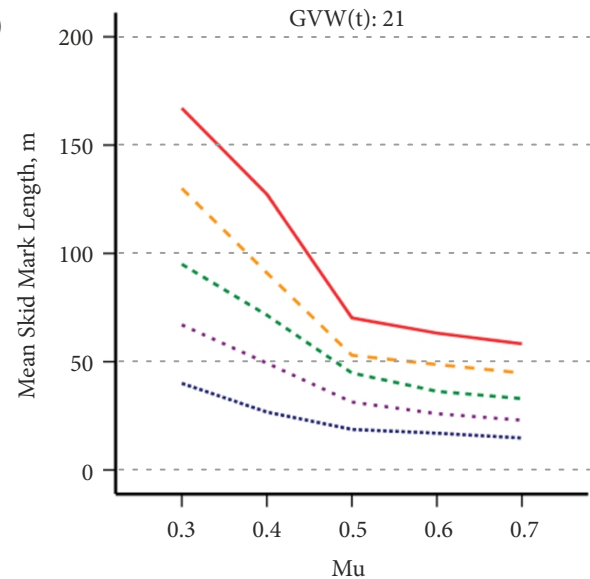

d)

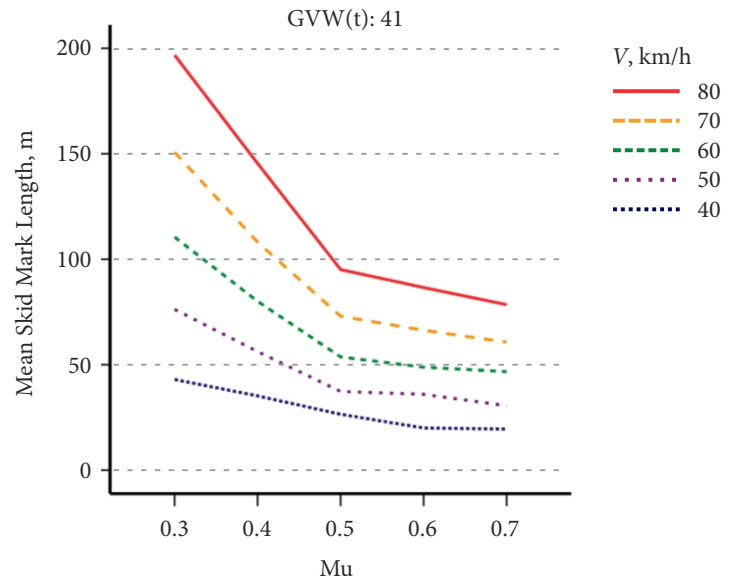

Figure 3. Effect of road coefficient of friction on Skidding Distance under different Gross Vehicle Weights and speed conditions

a)

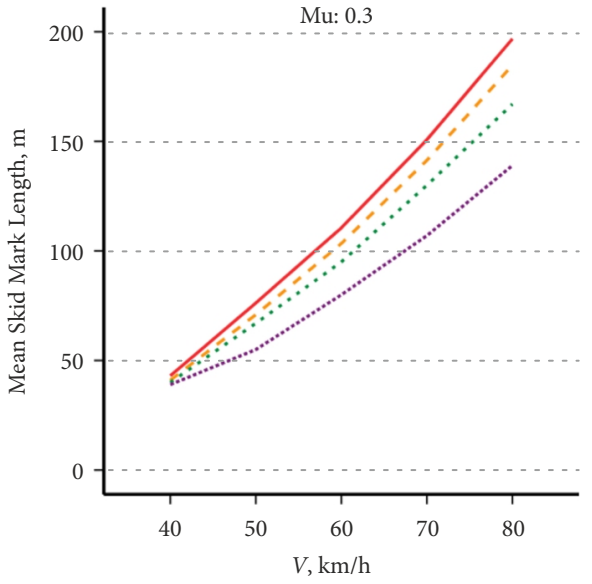

b)

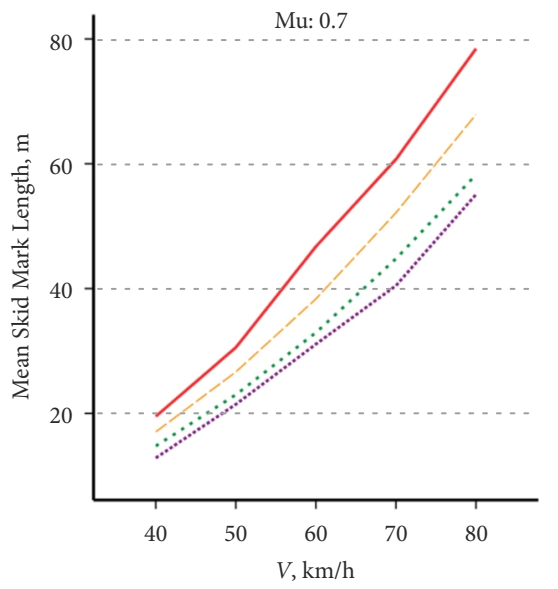

GVW (t)

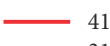

- 31 $\ldots \ldots .21$

Figure 4. Effect of heavy vehicle traveling speeds on Skidding Distance for different $\mu$ and Gross Vehicle Weights

\subsection{Assessment of correlation between Skidding Distance and influential factors}

A further bivariate correlation analysis of data reported in Table 6 was conducted to verify how strong the correlation is between all influential factors and SD.

Analysis of the data, using Pearson correlation coefficient, $r$, indicated the coefficient of friction was signifi- cantly negatively correlated with the mean ratings of the $\mathrm{SD}$, with $r(98)=-0.572$ and $p$-value, $p=0.00$. It means increases in the road coefficient of friction $(\mu)$ are associated with decreases in the rating of skidding distance. On the other hand, for slippery roads, heavy vehicle skidding distance is longer, so the condition is more dangerous. 
Table 6. Pearson correlations between Skidding Distance and influential factors

\begin{tabular}{|l|l|c|c|c|c|}
\hline \multicolumn{2}{|c|}{} & Skidding Distance (SD), m & Vehicle speed, km/h & $\mu$ & Gross Vehicle Weight, $\mathrm{r}$ \\
\hline \multirow{3}{*}{$\begin{array}{l}\text { Skidding Distance or } \\
\text { Skid Mark Length, } \mathrm{m}\end{array}$} & Pearson correlation & 1 & $0.694^{* *}$ & $-0.572^{\star *}$ & $0.491^{\star}$ \\
\cline { 2 - 7 } & Sig. (2-tailed) & & 0.000 & 0.000 & 0035 \\
\cline { 2 - 7 } & $N$ & 100 & 100 & 100 & 100 \\
\hline
\end{tabular}

Notes: ${ }^{\star *}$ correlation is significant at the 0.01 level (2-tailed); ${ }^{\star}$ correlation is significant at the 0.05 level (2-tailed).

Meanwhile, the positive correlation between SD and vehicle speed $(r=0.694, p<0.01)$, as well as the similar correlation between SD and GVW $(r=0.491 p<0.05)$, were determined to be significantly based on the $p$-values. Therefore, it is obvious that these factors, especially the GVW, cannot be ignored in skidding distance estimation models, for instance as seen from the conventional formula (Eq. (2)).

\subsection{Heavy vehicle Skidding Distance (SD) prediction model for accident reconstruction}

Accordingly, it is already known that the vehicle load, speed, and road surface condition need to be considered in SD modelling, as they do have effects that cannot be ignored. Consequently, a mathematical model for SD was derived to provide a reliable SD estimation. The proposed model not only incorporated vehicle speed and road coef- ficient of friction as in the usual "Skid to Stop Formula", but also GVW simultaneously. The model was based on non-linear multiple regression and expressed as Eq. (3):

$$
\frac{\mathrm{SD}}{\mu_{j}}=a w+b,
$$

where $\left\{\begin{array}{l}a=C_{1} V+C_{2} \\ b=C_{3} V+C_{4}\end{array} ; \mathrm{SD}\right.$ - skidding distance, $\mathrm{m} ; \mu_{j}-$ road surface coefficient of friction $(j=0.3$ to 0.7$) ; w-$ heavy vehicle GVW, $t ;-$ heavy vehicle driving speed, $\mathrm{km} / \mathrm{h}$.

In the multiple regression, the first regression calculation involved estimating the coefficients of the regression lines, $a$ and $b$ in Eq. (3) for various speeds. The values of these coefficients, as well as the $p$-values and the coefficients of determination, $R^{2}$ values for all cases, are stated in Table 7. An additional regression calculation was

Table 7. Regression coefficients $a$ and $b$

\begin{tabular}{|c|c|c|c|c|c|c|c|}
\hline$\mu$ & $V, \mathrm{~km} / \mathrm{h}$ & $a$ & $p$-value $(a)$ & $b$ (constant) & $p$-value $(b)$ & $R^{2}$ & $\mathrm{~N}$ \\
\hline \multirow{5}{*}{0.3} & 40 & 0.130 & 0.017 & 37.370 & 0.049 & 0.966 & \multirow{5}{*}{4} \\
\hline & 50 & 0.677 & 0.032 & 49.698 & 0.005 & 0.936 & \\
\hline & 60 & 1.000 & 0.016 & 71.235 & 0.003 & 0.967 & \\
\hline & 70 & 1.426 & 0.024 & 95.194 & 0.004 & 0.952 & \\
\hline & 80 & 1.911 & 0.017 & 122.194 & 0.003 & 0.966 & \\
\hline \multirow{5}{*}{0.4} & 40 & 0.396 & 0.019 & 18.114 & 0.007 & 0.962 & \multirow{5}{*}{4} \\
\hline & 50 & 0.438 & 0.028 & 38.237 & 0.003 & 0.945 & \\
\hline & 60 & 0.425 & 0.010 & 62.050 & 0.000 & 0.979 & \\
\hline & 70 & 1.040 & 0.012 & 67.365 & 0.002 & 0.975 & \\
\hline & 80 & 1.456 & 0.048 & 88.234 & 0.011 & 0.906 & \\
\hline \multirow{5}{*}{0.5} & 40 & 0.289 & 0.041 & 13.726 & 0.015 & 0.920 & \multirow{5}{*}{4} \\
\hline & 50 & 0.266 & 0.021 & 25.759 & 0.002 & 0.958 & \\
\hline & 60 & 0.386 & 0.014 & 37.059 & 0.001 & 0.971 & \\
\hline & 70 & 0.749 & 0.037 & 40.216 & 0.011 & 0.927 & \\
\hline & 80 & 1.104 & 0.008 & 48.141 & 0.003 & 0.984 & \\
\hline \multirow{5}{*}{0.6} & 40 & 0.161 & 0.008 & 13.629 & 0.001 & 0.984 & \multirow{5}{*}{4} \\
\hline & 50 & 0.429 & 0.012 & 17.581 & 0.006 & 0.976 & \\
\hline & 60 & 0.476 & 0.033 & 28.155 & 0.008 & 0.935 & \\
\hline & 70 & 0.717 & 0.018 & 35.653 & 0.006 & 0.965 & \\
\hline & 80 & 0.975 & 0.014 & 45.635 & 0.005 & 0.973 & \\
\hline \multirow{5}{*}{0.7} & 40 & 0.222 & 0.002 & 10.268 & 0.001 & 0.997 & \multirow{5}{*}{4} \\
\hline & 50 & 0.310 & 0.004 & 17.366 & 0.016 & 0.968 & \\
\hline & 60 & 0.523 & 0.037 & 23.687 & 0.015 & 0.988 & \\
\hline & 70 & 0.681 & 0.010 & 31.839 & 0.004 & 0.980 & \\
\hline & 80 & 0.797 & 0.023 & 44.193 & 0.006 & 0.950 & \\
\hline
\end{tabular}


Table 8. Regression coefficients $C_{1}$ to $C_{4}$

\begin{tabular}{|c|c|c|c|c|c|c|c|c|}
\hline$\mu$ & $C_{1}$ & $C_{2}$ & $C_{3}$ & $C_{4}$ & $R^{2}(a)$ & $R^{2}(b)$ & $N(a)$ & $N(b)$ \\
\hline \multirow{2}{*}{0.3} & 0.043 & -1.558 & 2.151 & -53.948 & \multirow{2}{*}{0.995} & \multirow{2}{*}{0.984} & \multirow{2}{*}{5} & \multirow{2}{*}{5} \\
\hline & 0.000 & 0.001 & 0.001 & 0.012 & & & & \\
\hline \multirow{2}{*}{0.4} & 0.027 & -0.822 & 1.694 & -46.821 & \multirow{2}{*}{0.813} & \multirow{2}{*}{0.973} & \multirow{2}{*}{5} & \multirow{2}{*}{5} \\
\hline & 0.036 & 0.153 & 0.019 & 0.002 & & & & \\
\hline \multirow{2}{*}{0.5} & 0.021 & -0.709 & 0.833 & -16.992 & \multirow{2}{*}{0.856} & \multirow{2}{*}{0.961} & \multirow{2}{*}{5} & \multirow{2}{*}{5} \\
\hline & 0.024 & 0.105 & 0.003 & 0.065 & & & & \\
\hline \multirow{2}{*}{0.6} & 0.019 & -0.598 & 0.821 & -21.120 & \multirow{2}{*}{0.966} & \multirow{2}{*}{0.979} & \multirow{2}{*}{5} & \multirow{2}{*}{5} \\
\hline & 0.003 & 0.018 & 0.001 & 0.011 & & & & \\
\hline \multirow{2}{*}{0.7} & 0.015 & -0.406 & 0.823 & -23.923 & \multirow{2}{*}{0.986} & \multirow{2}{*}{0.981} & \multirow{2}{*}{5} & \multirow{2}{*}{5} \\
\hline & 0.001 & 0.008 & 0.001 & 0.001 & & & & \\
\hline
\end{tabular}

then performed to determine the coefficients, $C_{i}$ in Eq. (3) where $i=1,2,3$ and 4 . These coefficient values and the corresponding $R^{2}$ values for all cases are described in Table 8 .

Based on the coefficient values in Tables 7-8, an efficient model for SD estimation that incorporates GVW, speed and road coefficient of friction as the factors, is obtained. For the regression model validation, with a comparison among the SD determined from the model with those obtained from multi-body dynamic simulation, it is found that the two means of determining SD are in good agreement with each other, and it is predicted with less than $4 \%$ error, which is illustrated in Figure 5. In general, the regression model matches the simulation and the experimental results very well, and it is an improvement over the traditional formula. Therefore, it is a reliable means of estimating SD without the need for detailed simulation.

The findings strongly support the road safety and accident reconstruction reports on crash injury (Raftery, Grigo, \& Woolley, 2008). High crash rates have been reported for overloaded trucks due to the inefficiency of brake performance (Aliakbari \& Moridpoure, 2016).

Finally, it is worth to elaborate slightly on the applicability of the obtained SD estimation model. With the emergency braking situation considered for straight and even road section, this model is logically applicable to skidding distance estimation in straight-line braking

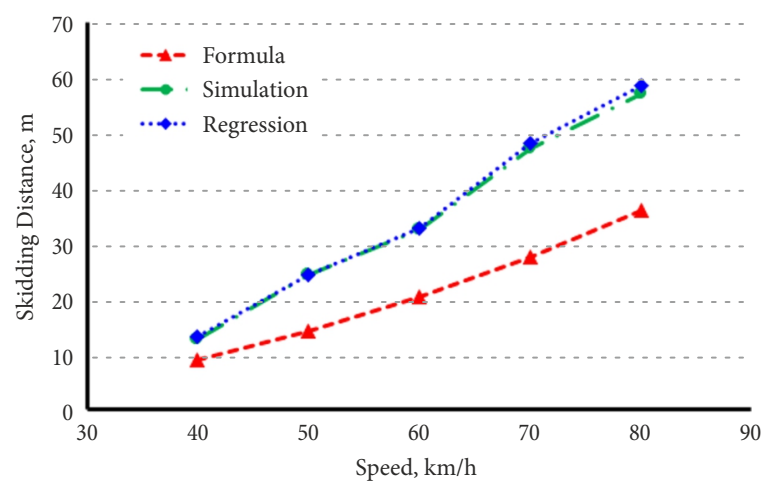

Figure 5. Comparison of Skidding Distance between model, simulation, and traditional formula events. It is naturally expected that the skidding distance will be different for braking situations involving other types of the road section, for instance, curved road section and gradient road section. For the former, it is expected that the skidding distance will be longer due to the lower longitudinal tire traction in the presence of lateral component due to cornering manoeuver. This needs to be incorporated in the estimation model. Meanwhile, for the latter, the effect on skidding distance will generally be due to the transverse vehicle weight component, with the altered skidding distance dependent on the slope of the gradient road section.

\section{Conclusion}

Within the context of the research:

1. This study has confirmed that the skidding distance of a heavy vehicle is not dominated by a single factor, but rather is dependent on various conditions, including vehicle load, vehicle speed, and the road surface condition.

2. As expected, the simulation results have shown an increase in Gross Vehicle Weight, speed and a decrease in the road coefficient of friction lead to notably greater skidding distance which poses a safety risk. Therefore, it is deduced that all three factors are significant and have to be incorporated in the estimation of skidding distance due to emergency braking situation.

3. By considering these factors, the novel non-linear regression skidding distance model introduced in this study is a step forward from the existing skidding formula.

4. The model offers an efficient and reliable way of estimating the skidding distance of the heavy vehicle as it has been proven to be similarly accurate as the detailed multi-body simulation. The model is particularly useful to the area of accident reconstruction, as it allows a sufficiently accurate prediction of skid mark length based on vehicle and road parameters, in addition to providing a general understanding of the behaviour of a heavy vehicle during braking. 


\section{Acknowledgements}

The authors would like to thank the Ministry of Science, Technology, and Innovation (MOSTI) of Malaysia for the financial support extended to the research project " $D y$ namic Rollover Warning System for Heavy Vehicle Using Weight in Motion Technology" (MOSTI Grant No. 03-0103-SF0772). The authors would like to extend gratitude and appreciation to PPP fund (Peruntukan Penyelidikan Pascasiswazah), (Project No: PG108-2013B) from Centre of Research Grant Management, University Malaya and to acknowledge the financial support provided by University of Malaya under the Equitable Society Research Cluster (ESRC) research grant RP006C-13 SBS.

\section{References}

Abdullah, A. S. (2011). Development of integrated weigh-in-motion system and analysis of traffic flow characteristics considering vehicle weight. The University of Tokushima Japan.

Aliakbari, M., \& Moridpoure, S. (2016). Management of truck loading weight: a critical review of the literature and recommended remedies. In E. Jud \& G. Lodewijks (Ed.) Proceedings of the 5th International Conference "Transportation and Traffic Engineering”: selected papers, vol. 81, 6-10 July, 2016. Lucerne, Switzerland. MATEC Web of Conferences 81, 03007 (2016). https://doi.org/10.1051/matecconf/20168103007

Asi, I. M. (2007). Evaluating skid resistance of different asphalt concrete mixes. Building and Environment, 42(1), 325-329. https://doi.org/10.1016/j.buildenv.2005.08.020

Bartlett, W., \& Wright, W. (2010). Braking on dry pavement and gravel with and without ABS. SAE Technical Paper No: 201001-0066. https://doi.org/10.4271/2010-01-0066

Bedsworth, K., Butler, R., Rogers, G., Breen, K., \& Fischer, W. (2013). Commercial vehicle skid distance testing and analysis. SAE Technical Paper No: 2013-01-0771.

Bullen, F., \& Ruller, J. (1998). Reconstructing crashes involving emergency braking on wet roads. International Journal of Crashworthiness, 3(1), 65-72.

https://doi.org/10.1533/cras.1998.0062

Chen, S., \& Chen, F. (2009). Simulation-based assessment of vehicle safety behavior under hazardous driving conditions. Journal of transportation engineering, 136(4), 304-315. https://doi.org/10.1061/(ASCE)TE.1943-5436.0000093

Dee, T. S., \& Sela, R. J. (2003). The fatality effects of highway speed limits by gender and age. Economics Letters, 79(3), 401408. https://doi.org/10.1016/S0165-1765(03)00026-0

Deur, J., Asgari, J., \& Hrovat, D. (2004). A 3D brush-type dynamic tire friction model. Vehicle System Dynamics, 42(3), 133-173. https://doi.org/10.1080/00423110412331282887

Ervin, R., \& Winkler, C. (1988). Estimation of the probability of wheel lockup. International journal of vehicle design, 9(4), 423-437.

Fancher, P., \& Campbell, K. (1995). Vehicle characteristics affecting safety and truck size and weight regulations. US Department of Transportation, Washington, DC.

Flintsch, G. W., McGhee, K. K., de León Izeppi, E., \& Najafi, S. (2012). The little book of tire pavement friction (23 p.). Pavement Surface Properties Consortium.

Garrott, W. R., \& Guenther, D. A. (1982). Determination of Precrash parameters from Skid Mark Analysis. Journal of Transportation Research Record 893, 38-46.
Ghadiri, S., Prasetijo, J., Sadullah, A., Hoseinpour, M., \& Sahranavard, S. (2013). Intelligent speed adaptation: preliminary results of on-road study in Penang, Malaysia. IATSS research, 36(2), 106-114. https://doi.org/10.1016/j.iatssr.2012.08.001

Gobbi, M., Mastinu, G., \& Previati, G. (2014). The effect of mass properties on road accident reconstruction. International Journal of Crashworthiness, 19(1), 71-88.

https://doi.org/10.1080/13588265.2013.853965

Goudie, D. W., Bowler, J. J., Brown, C. A., Heinrichs, B. E., \& Siegmund, G. (2000). Tire friction during locked wheel braking. SAE Technical Paper No:2000-01-1314.

https://doi.org/10.4271/2000-01-1314

Gustafsson, F. (1997). Slip-based tire-road friction estimation. Automatica, 33(6), 1087-1099.

https://doi.org/10.1016/S0005-1098(97)00003-4

Hall, J. W., Smith, K. L., Titus-Glover, L., Wambold, J. C., Yager, T. J., \& Rado, Z. (2009). Guide for pavement friction: national cooperative highway research program (244 p.). Transportation Research Board of the National Academies.

Harwood, D. W., Torbic, D. J., Richard, K. R., Glauz, W. D., \& Elefteriadou, L. (2003). Review of truck characteristics as factors in roadway design (194 p.). Report No. NCHRP Report 505. Transportation Research Board-National Research Council, Washington DC.

Henry, J. J. (2000). Evaluation of pavement friction characteristics (66 p.). Report No. NCHRP SYNTHESIS 291. Transportation Research Board-National Research Council, Washington DC.

Jones, I. S. (2013). The effect of vehicle characteristics on road accidents (234 p.) (1st ed.). Elsevier.

Kim, K. B., Jung, W. T., Ryu, T. S., \& Oh, Y. T. (2012). A study on acceleration of transient brake section and skidding section. Journal of Korean Society of Transportation, 30(5), 83-90. https://doi.org/10.7470/jkst.2012.30.5.083

Limpert, R., \& Andrews, D. F. (1987). Analysis of truck braking accidents. SAE Technical Paper No:870504. https://doi.org/10.4271/870504

Neptune, J. A., Flynn, J. E., Chavez, P. A., \& Underwood, H. W. (1995). Speed from skids: a modern approach. SAE Technical Paper No: 950354.

Noon, R. K. (1992). Introduction to forensic engineering. CRC Press, Florida.

Noyce, D. A., Bahia, H. U., Yambo, J. M., \& Kim, G. (2005). Incorporating road safety into pavement management: maximizing asphalt pavement surface friction for road safety improvements. Draft Literature Review and State Surveys, Midwest Regional University Transportation Center (UMTRI), Madison, Wisconsin.

Oh, Y., \& Lee, H. (2014). Characteristics of a tire friction and performances of a braking in a high speed driving. Advances in Mechanical Engineering, 6, 260428.

https://doi.org/10.1155/2014/260428

Ong, G., \& Fwa, T. (2009). Modeling skid resistance of commercial trucks on highways. Journal of Transportation Engineering, 136(6), 510-517.

https://doi.org/10.1061/(ASCE)TE.1943-5436.0000116

Pacejka, H. B. (2006). Tyre and vehicle dynamics (624 p.) (2nd ed.). Elsevier.

Raftery, S., Grigo, J., \& Woolley, J. (2008). Heavy vehicle road safety: research scan (110 p.). Research Report No. CASR100, Centre for Automotive Safety Researc, The University of Adelaide, Australia. 
Ray, L. R. (1997). Nonlinear tire force estimation and road friction identification: simulation and experiments. Automatica, 33(10), 1819-1833.

https://doi.org/10.1016/S0005-1098(97)00093-9

Schmid, M. (2011). Tire modeling for multibody dynamics applications (76 p.). Research Report No. University of Wisconsin, Madison.

Seipel, G., Baumann, F., Hermanutz, R., \& Winner, H. (2013). Analysis of the influence of vehicle dynamic parameters on tire marks. Tire Science And Technology, 41(3), 196-213.

Sharizli, A., Ramli, R., Karim, M. R., \& Abdullah, A. S. (2014). Simulation and analysis on the effect of gross vehicle weight on braking distance of heavy vehicle. Applied Mechanics and Materials, 564(1), 77-82.

https://doi.org/10.4028/www.scientific.net/AMM.564.77

Sharizli, A., Ramli, R., Karim, M. R., \& Saifizul, A. (2013). Novel method of determining braking distance of heavy vehicle using advanced simulation technique. Proceedings of the $3 \mathrm{rd}$ International Conference on Civil, Transport and Environment Engineering, 25-26 December, 2013. Bangkok, Thailand.

Sharizli, A., Ramli, R., Karim, M. R., \& Saifizul, A. (2015). New method for distance-based close following safety indicator. Traffic Injury Prevention, 16(2), 190-195.

https://doi.org/10.1080/15389588.2014.921913
Steets, J., Chan, B., Sandu, C., \& Ballew, B. (2010). Multibody dynamics approach to the modeling of friction wedge elements for freight train suspensions. II: Applications. Journal of Transportation Engineering, 136(8), 717-726. https://doi.org/10.1061/(ASCE)0733-947X(2010)136:8(717)

Vangi, D., \& Virga, A. (2007). Evaluation of emergency braking deceleration for accident reconstruction. Vehicle System Dynamics, 45(10), 895-910. https://doi.org/10.1080/00423110701538320

Wallman, C.-G., \& Åström, H. (2001). Friction measurement methods and the correlation between road friction and traffic safety: a literature review (47 p.). Report No. VTI meddelande 911A, Swedish National Road and Transport Research Institute, Sweden.

Xiao, J., Kulakowski, B., \& EI-Gindy, M. (2000). Prediction of risk of wet-pavement accidents: Fuzzy Logic Model. Transportation research record. Journal of the Transportation Research Board, (1717), 28-36. https://doi.org/10.3141/1717-05

Xuanfeng, W., Yingchun, L., Guang, S., Chaosheng, H., \& Guozeng, Y. (2011). A study on the asynchronous brake lock-up of a statically indeterminate tractor with an air suspension. Proceedings of the Institution of Mechanical Engineers, Part D: Journal of Automobile Engineering, 226(4), 507-516. https://doi.org/10.1177/0954407011423132 